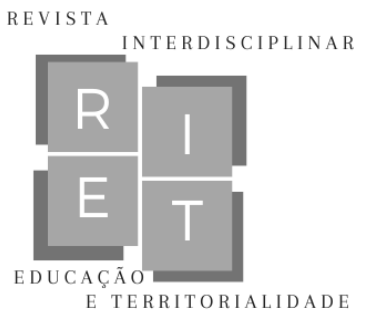

\title{
A Música Ensina: Educação e Multiculturalismo
}

\author{
The Music Teaches: Education and Multiculturalism
}

La Música Enseña: Educación y Multiculturalismo

\begin{abstract}
Alexandre dos Santos ${ }^{1}$
Programa de Pós-graduação em Educação nas Ciências da Universidade do Noroeste do Estado do

Rio Grande do Sul (UNIJUÍ)

Santo Ângelo, Rio Grande do Sul, Brasil

E-mail: ale.lexotrio@hotmail.com

ORCID: 0000-0001-8510-1537
\end{abstract}

Resumo: Este texto consiste numa análise teórica das possibilidades educacionais e lúdicas da música e da arte na construção do conhecimento. Apresenta a reflexão de como as canções refletem o contexto cultural, político, social e econômico ao qual os compositores estão inseridos no momento de criação. Analisa a diversidade cultural presente nas regiões brasileiras, enfatiza como a música tradicionalista "conta" a história do Rio Grande do Sul e como estas exerceram influência no Rock Gaúcho. Elenca questionamentos acerca das Ciências Humanas à luz da Arte e da especificidade da linguagem musical, o que enriquece a percepção aos conceitos vinculados ao Multiculturalismo, na medida em que a dimensão musical amplia as possibilidades de aprendizado.

Palavras-chave: Educação. Música. Multiculturalismo.

Abstract: This text consists of a theoretical analysis of the educational and recreational possibilities of music and art in the construction of knowledge. It presents a reflection on how the songs reflect the cultural, political, social and economic context in which composers are inserted at the time of creation. It analyzes the cultural diversity present in Brazilian regions, emphasizes how traditionalist music "tells" the history of Rio Grande do Sul and how these influenced Rock Gaucho. It lists questions about the Human Sciences in light of Art and the specificity of musical language, which enriches the perception of concepts linked to Multiculturalism, as the musical dimension expands the possibilities for learning.

Keywords: Education. Music. Multiculturalism.

Resumen: Este texto consiste en un análisis teórico de las posibilidades educativas y recreativas de la música y el arte en la construcción del conocimiento. Presenta una reflexión

\footnotetext{
${ }^{1}$ Doutorando em Educação nas Ciências pelo Programa de Pós-graduação em Educação nas Ciências da Universidade do Noroeste do Estado do Rio Grande do Sul (UNIJUÍ), graduado em História pela Universidade Regional Integrada do Alto Uruguai e das Missões (URI Santo Ângelo RS), especialista em Game Design pela Universidade Positivo, Mestre em Educação nas Ciências pela Universidade Regional do Noroeste do Estado do Rio Grande do Sul (UNIJUÍ). Professor do magistério estadual do Rio Grande do Sul. Atua nas seguintes áreas de pesquisa: Gamificação, Cinema, Música e Novas Abordagens Metodológicas no Ensino de História.
} 


\section{A música ensina: educação e multiculturalismo}

sobre cómo las canciones reflejan el contexto cultural, político, social y económico en el que se insertan los compositores en el momento de su creación. Analiza la diversidad cultural presente en las regiones brasileñas, enfatiza cómo la música tradicionalista "cuenta" la historia de Rio Grande do Sul y cómo ésta influyó en el Rock Gaucho. Enumera preguntas sobre las Ciencias Humanas a la luz del Arte y la especificidad del lenguaje musical, que enriquece la percepción de conceptos vinculados al Multiculturalismo, ya que la dimensión musical amplía las posibilidades de aprendizaje.

Palabras Clave: Educación. Música. Multiculturalismo.

Data de recebimento: $15 / 04 / 2021$

Data de aprovação: 10/06/2021

DOI: $10.30612 /$ riet.v2i2.14565

\section{Introdução}

A música faz parte da nossa vida cotidiana, na medida em que invadimos o seu universo, de várias formas. E, assim como outras artes, sensibiliza nossos sentimentos através de poesias ritmadas. Este texto ${ }^{2}$, que utiliza uma metodologia baseada em uma perspectiva teórica, estabelece uma análise das canções nacionais e regionais, pertinentes ao tema do multiculturalismo, da identidade cultural, da diversidade cultural brasileira, da cultura gaúcha e missioneira, e discorre sobre como a música é um valioso estímulo e um instrumento de aprendizagem.

Diante disso, consiste numa análise teórica das possibilidades educacionais e lúdicas da música e da arte na construção do aprendizado, já que as canções refletem o contexto cultural, político, social e econômico ao qual os compositores estão inseridos no momento de criação. Aborda a diversidade cultural presente nas regiões brasileiras, enfatiza como a cultura gaúcha e a cultura missioneira estão presentes na música e nas obras de arte, assim como essas exerceram influência no Rock Gaúcho.

Discute-se o multiculturalismo neste texto pelo viés do Multiculturalismo Crítico, para o qual a diversidade não é apenas como uma meta, mas uma afirmação de crítica e compromisso com a justiça social. A diferença é vista como produto da história, da cultura, das relações ideológicas e de estabelecimento das forças de poder. Assim,

A perspectiva que estou chamando de multiculturalismo crítico compreende a representação de raça, classe e gênero como resultado de

2 Este artigo é a fundamentação do documentário homônimo "A Música Ensina: Educação e Multiculturalismo" que se encontra em fase final de produção. O projeto foi aprovado pelo educador, músico e autor do texto, fomentado pelo edital Multiartes Cidades dos Anjos, promovido pela prefeitura de Santo Ângelo - RS, em apoio aos artistas e à cultura neste momento de pandemia do Coronavírus (Covid-19). O documentário terá a duração aproximada de 60 min. Com a preocupação de possibilitar a democratização, o acesso cultural e a inclusão, o filme será disponibilizado de forma gratuita no Youtube e nas redes sociais (Facebook e Instagram).

RIET- ISSN 2676-0355, Dourados, v. 2, n. 2, p. 391 a 408, jan./jun., 2021 


\section{A música ensina: educação e multiculturalismo}

lutas sociais mais amplas sobre signos e significações e, neste sentido, enfatiza não apenas o jogo textual e o deslocamento metafórico como forma de resistência (como no caso do multiculturalismo liberal de esquerda), mas enfatiza a tarefa central de transformar as relações sociais, culturais e institucionais nas quais os significados são gerados (McLAREN, 2000, p. 123).

Na música Béradêro, Chico César possibilita, aos apreciadores, o reconhecimento das diferentes etnias e culturas brasileiras, assim como submete uma análise das relações sociais surgidas a partir dessas diferenças, como é possível notar:

Os olhos tristes da fita / Rodando no gravador / Uma moça cosendo roupa
/ Com a linha do Equador / E a voz da Santa dizendo / O que é que eu tô
fazendo / Cá em cima desse andor / A tinta pinta o asfalto / Enfeita a alma
motorista / É a cor na cor da cidade Batom no lábio nortista / O olhar vê
tons tão sudestes / E o beijo que vós me nordestes / Arranha céu da boca
paulista / Cadeiras elétricas da baiana / Sentença que o turista cheire / E os
sem amor os sem teto / Os sem paixão sem alqueire / No peito dos sem
peito uma seta / E a cigana analfabeta / Lendo a mão de Paulo Freire / A
contenteza do triste / Tristezura do contente / Vozes de faca cortando /
Como o riso da serpente / São sons de sins, não contudo / Pé quebrado
verso mudo / Grito no hospital da gente / Catulé do Rocha Praça de guerra
/ Catulé do Rocha / Onde o homem bode berra / Bari bari bari / Tem uma
bala no meu corpo / Bari bari bari / E não é bala de coco / São sons, são
sons de sins / Pé quebrado, verso mudo / Grito no hospital da gente
(GONÇALVEZ, 1995).

Tais paradoxos se fazem presentes, a todo momento, na estrutura social do Brasil. Não obstante, com essa canção, composta por trocadilhos que remetem às situações corriqueiras e cotidianas da realidade brasileira, é possível refletir acerca da importância de temas referentes ao multiculturalismo e das desigualdades sociais e da diversidade étnicas da população brasileira.

\section{Educação multicultural por meio da música}

Considerando o intuito de tecer relações entre a música e a Educação, torna-se pertinente, neste momento, a construção dos conceitos centrais que nortearão o referencial teórico deste trabalho. Para isso, é necessário também reconhecer como estes conceitos se encontram interligados.

Nesse âmbito, a cultura deve ser compreendida como o conjunto de elementos crenças, tradições, hábitos, vestimenta, idioma, culinária, etc. - que caracterizam os grupos humanos, e interessam dois conceitos importantes para compreendê-la: o de representação e o de identidade. Conforme os escritos de Stuart Hall (2006), a representação atua 


\section{A música ensina: educação e multiculturalismo}

simbolicamente para classificar o mundo de nossas relações no seu interior. As questões de representação estão ligadas à identidade e à diferença. Ao examinar sistemas de representação é necessário analisar a relação entre cultura e significado.

É por meio dos significados produzidos pelas representações que damos sentido à nossa experiência e àquilo que somos. Podemos inclusive, sugerir que esses sistemas simbólicos tornam possível aquilo que somos e aquilo no qual podemos nos tornar. A representação, compreendida como um processo cultural, estabelece identidades individuais e coletivas e os sistemas simbólicos nos quais ela se baseia (WOODWARD, 2013, p. 18).

Para Kathryn Woodward (2013), a identidade é marcada por meio de símbolos e por meio de exemplos. Existe uma associação entre a identidade da pessoa e as coisas que uma pessoa usa.

Só podemos compreender os significados envolvidos nesses sistemas se tivermos alguma ideia sobre quais posições-de-sujeito eles produzem e como nós, como sujeitos, podemos ser posicionados em seu interior. Aqui, estaremos tratando de um outro momento do "circuito da cultura": aquele em que o foco se desloca dos sistemas de representação para as identidades produzidas por aqueles sistemas (WOODWARD, 2013, p. 17).

Portanto, em uma perspectiva plural, as culturas podem ser compreendidas como diferentes categorias sociológicas, como organização social, religiosa e econômica. Representam, ao menos, três elementos no cotidiano dos sujeitos humanos: o que as pessoas pensam; aquilo que fazem e o modo como fazem; e o material que produzem.

Para tanto, Geertz (1989) salienta que o significado é essencialmente constituído por signos, já que:

O homem é um animal amarrado a teias de significados que ele mesmo teceu, assumo a cultura como sendo essas teias e a sua análise: portanto, não como uma ciência experimental em busca de leis, mas uma ciência interpretativa, à procura do significado (GEERTZ, 1989, p. 4).

Nesse sentido, cada agrupamento de "animais amarrados", isto é, com suas práticas sociais específicas, produzirá "teias de significados" diferentes. Quanto a isso, é preciso supor que o desenvolvimento da humanidade está marcado por distintos contatos e conflitos entre as diversas "teias". Logo, é o contato com essas diferentes teias que resulta na transformação das culturas, sendo que, para que isso ocorra, o mesmo homem pode ser movido por forças externas ou internas, mas, muitas vezes, por ambas.

A partir da relação de contato, Peter McLaren (1991) definirá a cultura como:

RIET- ISSN 2676-0355, Dourados, v. 2, n. 2, p. 391 a 408, jan./jun., 2021 


\section{A música ensina: educação e multiculturalismo}

Formada fundamentalmente por rituais inter-relacionados e sistemas de rituais, é um padrão historicamente transmitido de significados encarnados em símbolos, um sistema de concepções herdadas, expressas em formas simbólicas por meio dos quais os homens comunicam, perpetuam e desenvolvem seu conhecimento e atitudes em relação à vida. A cultura é uma construção que permanece como uma realidade consistente e significativa através da organização abrangente de rituais e sistemas simbólicos (McLAREN, 1991, p. 32-33).

As obras artísticas (filmes, músicas, pinturas ou outras representações) são discursos de um contexto e refletem uma cultura vigente, assim, são elaboradas de acordo com as características nas quais elas estão imersas. As suas criações e suas utilizações têm a capacidade de romper com essa construção, ou, pelo menos, reformular e questionar a imposição de uma estrutura social. Stuart Hall (2006, p. 50) afirma que

a formação de uma cultura nacional contribui para criar padrões de alfabetização universais, generalizou uma única língua vernacular como o meio dominante de comunicação em toda a nação, criou uma cultura homogênea e manteve instituições culturais nacionais.

A manutenção ou não deste discurso é opção das instituições presentes na sociedade, e cada instituição escolar, universidade ou centro de educação - escolar ou não-escolar, intencional ou não-intencional (LIBÂNEO, 2013) -, tem o poder de formar e definir a sua finalidade, tanto ideológica como de intervenção.

Para dar suporte ao que se dispõe este texto, que é conceituar a cultura de forma a reconhecê-la enquanto categoria plural, Canclini (1998) concebe a cultura como um processo em constante transformação. Então, a partir do conceito de relativismo cultural, ressalta que todas as culturas possuem formas próprias de organização e características que lhes são intrínsecas e que precisam ser respeitadas. $\mathrm{O}$ autor considera o consumo, como categoria de análise, uma das principais características da cultura contemporânea. Desse modo, ainda que leve em consideração o fenômeno da globalização, afirma que os aspectos regionais e locais também possuem importância dentro das comunidades (CANCLINI, 1998).

Não obstante, neste escopo, Santos (2003) auxilia a compreender como a cultura facilita o entendimento da formação da identidade "e de alteridades no mundo contemporâneo, um recurso para a afirmação da diferença e da exigência do seu reconhecimento e um campo de lutas e contradições" (SANTOS, 2003, p. 28).

RIET- ISSN 2676-0355, Dourados, v. 2, n. 2, p. 391 a 408, jan./jun., 2021 


\title{
A música ensina: educação e multiculturalismo
}

Além disso, a cultura é entendida, então, como híbrida, dinâmica, transnacional e dotada de uma capacidade infinita de criar novos símbolos (signos e significados) (BHABHA, 1998; CANCLINI, 1998). Para Silva (1994, p. 14), A “cultura significa uma forma completa de vida, material, intelectual e espiritual, incluindo o comportamento simbólico da vida cotidiana de uma sociedade”. Nesse âmbito, é possível afirmar que as identidades são reconstruídas dentro do grupo e de acordo com a cultura. Logo, é necessário que a escola compreenda que, no processo histórico, as culturas passam por transformações. Não é que seja possível negar a tradição, mas deve-se compreender que, mesmo estando ligada ao passado, ela influência nas formas como as pessoas se relacionam com as novidades.

Em suma, portanto, a Educação multicultural "é percebida como uma via pela qual se promove o resgate de valores culturais ameaçados, de forma a garantir a pluralidade cultural" (CANEN, 2000, p. 138). Destarte, defende-se uma educação multicultural que problematize o engessamento de uma identidade nacional, que busque entender a dinamicidade e o hibridismo cultural, e que, dessa forma, lance um olhar crítico e desafiador a preconceitos e estereótipos, vislumbrando, por meio das práticas curriculares, o alcance de uma reflexão que valorize a cidadania plural.

Para discutir esta questão, por exemplo, é possível considerar o que os Parâmetros Curriculares Nacionais apontam como um dos objetivos do Ensino de História: "Conhecer características fundamentais do Brasil nas dimensões sociais, materiais e culturais como meio para construir progressivamente a noção de identidade nacional e pessoal e o sentimento de pertinência ao país" (BRASIL, 1998, p. 20). Salienta o documento que

\begin{abstract}
A investigação histórica passou a considerar a importância da utilização de outras fontes documentais, além da escrita, aperfeiçoando métodos de interpretação que abrangem os vários registros produzidos. A comunicação entre os homens, além de escrita, é oral, gestual, sonora e pictórica. [...] Abre-se aí um campo fértil às relações interdisciplinares, articulando os conhecimentos de História com aqueles referentes à Língua Portuguesa, à Literatura, à Música e a todas as Artes, em geral (BRASIL, 1998, p. 2122)
\end{abstract}

Entre as finalidades dos PCN's, encontra-se a de regulamentar o ensino de história, com a visão ampla de desenvolver os objetos do conhecimento e formar cidadãos que exerçam a criticidade e a cidadania, que digam respeito à contextualização sociocultural, ao objetivo de "situar as diversas produções da cultura - as linguagens, as artes, a filosofia, a

RIET- ISSN 2676-0355, Dourados, v. 2, n. 2, p. 391 a 408, jan./jun., 2021 


\section{A música ensina: educação e multiculturalismo}

religião, as ciências, as tecnologias e outras manifestações sociais - nos contextos históricos de sua constituição e significação" (BRASIL, 1998, p. 28).

Sendo a música definida como a "arte ou ciência de combinar os sons de modo que agradem ao ouvido; a que tira dos elementos dinamogênicos (ritmo, melodia, harmonia) as suas razões de agradar" (FERREIRA, 2010, p. 759), ela poderá ser utilizada na sala de aula como uma forma diferenciada de interpretação das fontes e dos fatos históricos.

Sons e ruídos estão impregnados no nosso cotidiano de tal forma que, na maioria das vezes, não tomamos consciência deles. Eles nos acompanham diariamente, como uma autêntica trilha sonora de nossas vidas, manifestando-se sem distinção nas experiências individuais ou coletivas (MORAES, 2000, p. 204).

A ciência histórica, e consequentemente seu ensino, precisa intentar compreender os elementos que formam o imaginário popular. A aproximação e a explicação da realidade social também são entendidas a partir da análise e da interpretação das canções que compõem os grupos de indivíduos ligados pelos mesmos elementos culturais. Para Moraes (2000, p. 218)

creio que as questões aqui realçadas alcançaram pelo menos três aspectos relevantes para a reflexão do historiador que pretende trabalhar com a canção popular: a linguagem da canção, a visão de mundo que ela incorpora e traduz, e, finalmente, a perspectiva social e histórica que ela revela e constrói [...] é bem provável que as canções possam esclarecer muitas coisas na história contemporânea que às vezes se supõem mortas ou perdidas na memória coletiva.

Segundo Moreira (2002), o multiculturalismo configura-se como uma tendência educacional inescapável do mundo ocidental, uma vez que a diversidade cultural e social originada das migrações faz parte de nossa sociedade, que está em processo crescente de globalização. Portanto, McLaren (2000) define quatro formas distintas de multiculturalismo: conservadora, humanista liberal, liberal de esquerda e crítica ou de resistência.

O multiculturalismo conservador se fundamenta no discurso de inferioridade cognitiva, cultural e moral dos diversos grupos sociais subalternos. Enaltece, dessa forma, a supremacia dos grupos dominantes, desconsidera as relações de poder e justifica sua superioridade pelas qualidades advindas dos aspectos da cultura do homem branco.

A forma de multiculturalismo humanista liberal, por sua vez, possui, como discurso, a existência de "igualdade" entre as culturas, uma vez que, por detrás das diferenças, existe

RIET- ISSN 2676-0355, Dourados, v. 2, n. 2, p. 391 a 408, jan./jun., 2021 


\section{A música ensina: educação e multiculturalismo}

uma igualdade essencial entre todos os indivíduos: a sua humanidade. Desconsidera as relações sociais e de exploração entre os homens e as mulheres.

Já o multiculturalismo liberal de esquerda enfatiza a igualdade das raças e descarta as diferenças específicas entre as culturas e as manifestações construídas historicamente. Considera que essa igualdade constitui a essência dos indivíduos, independente das relações de poder.

As concepções do multiculturalismo Crítico e de Resistência, que norteia a teoria deste trabalho, buscam compreender de que forma o discurso dominante constrói as representações e identidades dos indivíduos. Nessa perspectiva,

A educação multicultural seria uma via pela qual se superaria uma visão meramente folclórica ou exótica acerca da pluralidade cultural, bem como iria além do mero desenvolvimento de valores de "tolerância" e de "apreciação" da diversidade cultural [...] fomenta-se, acima de tudo, o desenvolvimento de uma conscientização crítica acerca do binômio pluralidade cultural e poder, e, consequentemente, acerca das práticas pedagógicas cotidianas que excluem as vozes ligadas a grupos socioculturais marginalizados (CANEN, 2000, p. 138).

Os educadores, principalmente aqueles ligados às Ciências Humanas, necessitam estar inteligíveis ao poder de enriquecimento cultural oriundo dos processos históricos para o reconhecimento da valorização das diferenças culturais. Essa forma de multiculturalismo concebe as diferenças como produto das relações sociais e tem sua ênfase na transformação social, a qual tem uma função imprescindível para a escola.

Importante ressaltar aqui que a Constituição Federal de 1988 passa a reconhecer a diversidade cultural como elemento constituidor da sociedade nacional. É importante essa menção, pois as políticas educacionais elaboradas na década seguinte, como os Parâmetros Curriculares Nacionais, mencionados anteriormente passam a refletir isso.

\section{A diversidade cultural das regiões brasileiras}

O Brasil foi formado historicamente por uma diversidade de povos. A herança colonialista europeia trouxe à tona, desde o começo de nossa história, a exploração e uma estrutura elitista. Dessa mistura, originou-se um país com proporções continentais, onde a nação se tornou diferente nos seus "quatro cantos". Estabelece-se, assim, um país heterogêneo, tanto no aspecto cultural, quanto no aspecto étnico. 


\title{
A música ensina: educação e multiculturalismo
}

Os quatro-Brasis foram definidos por Milton Santos e Maria Laura Silveira (2006) a partir do critério de acesso (ou da falta de acesso) ao "meio técnico-científicoinformacional". A informação e as finanças estão irradiadas de maneira desigual e distinta pelo nosso território. De acordo com os autores,

\begin{abstract}
Neste ponto da história do território brasileiro, parece lícito propor, a partir das premissas levantadas aqui, uma discussão em torno da possibilidade de propormos uma divisão regional baseada, simultaneamente, numa atualidade marcada pela difusão diferencial do meio técnico-científicoinformacional e nas heranças do passado. Cada região instala aquilo que, a cada momento, vem a constituir rugosidades diferentes. Essas rugosidades estão ligadas, de um lado, à tecnicidade dos objetos de trabalho e, de outro, ao arranjo desses objetos e às relações daí resultantes (SANTOS; SILVEIRA, 2006, p. 268).
\end{abstract}

A diversidade caracteriza a nação, a diferença enriquece a cultura e o conjunto dessa "mistura" forma a nossa sociedade. A música Homem Amarelo, da banda carioca O Rappa, apresenta em seus versos a temática da difusão étnica de nossa nação. "O Homem Amarelo do Samba do Morro / O Hip Hop do Santa Marta / Agarrar o louro na descida da ladeira / Malandro da baixada em terra estrangeira / A salsa cubana do negro oriental / Já é ouvida na central" (O RAPPA, 1999). Essa miscigenação está presente na paisagem urbana do Rio de Janeiro, que é o contexto de criação da canção. Tal pluralidade é evidenciada nos versos finais, onde também aparecem a questão da religiosidade (terreiros remetendo à religião da Umbanda) e da esperada igualdade entre as etnias: "Eu e a minha tribo brincando nos terreiros / Eu e a minha tribo nos terreiros do mundo / Só misturando pra ver o que vai dar / Só misturando pra ver o que vai dar / Cor da pele, sempre / Todo mundo é igual" (O RAPPA, 1999).

A questão referente às diferenças religiosas do Brasil, por exemplo, pode ser reforçada a partir da interpretação da canção Toda Menina Baiana, de Gilberto Gil, nos versos "Toda menina baiana tem um santo, que Deus dá / Toda menina baiana tem encanto, que Deus dá / Toda menina baiana tem um jeito, que Deus dá / Toda menina baiana tem defeito também que Deus dá" (GIL, 1979). O colonialismo perverso também está representado quando o autor fala em "Que Deus entendeu de dar a primazia / Pro bem, pro mal, primeiro chão na Bahia / Primeira missa, primeiro índio abatido também (...) Que Deus entendeu de dar toda magia / Primeiro carnaval, primeiro Pelourinho também / Que Deus deu" (GIL, 1979).

RIET- ISSN 2676-0355, Dourados, v. 2, n. 2, p. 391 a 408, jan./jun., 2021 


\section{A música ensina: educação e multiculturalismo}

Este contexto colonialista, contido no pensamento brasileiro, construiu as concepções de preconceito do indígena (citado na música anterior) e do negro, citado na música Olhos Coloridos, de Sandra de Sá. Observe a letra:

Os meus olhos coloridos / Me fazem refletir / Eu estou sempre na minha / E não posso mais fugir / Meu cabelo enrolado / Todos querem imitar / Eles estão baratinados / Também querem enrolar / Você ri da minha roupa / Você ri do meu cabelo / Você ri da minha pele / Você ri do meu sorriso / A verdade é que você / Tem sangue crioulo / Tem cabelo duro / Sarará crioulo / Sarará crioulo (COSTA, 1995).

Esta composição é fruto de ironia sobre o preconceito sofrido pelo compositor (Macau), que a compôs na década de 1970, após ser preso injustamente pela Polícia Militar do Rio de Janeiro em uma exposição de escolas públicas no Estádio de Remo da Lagoa. Como reflexo, representa a valorização da cultura afrodescendente e reafirma a ligação de todo o brasileiro com a sua composição étnica.

Já a música Asa Branca, de Luiz Gonzaga, reflete o espaço semiárido brasileiro e a sua influência no contexto cultural, como é possível perceber na letra:

Quando olhei a terra ardendo / Qual fogueira de São João / Eu perguntei a
Deus do céu, ai / Por que tamanha judiação / Que braseiro, que fornaia /
Nem um pé de plantação / Por falta d'água perdi meu gado / Morreu de
sede meu alazão / Inté mesmo a asa branca / Bateu asas do sertão / Entonce
eu disse, adeus Rosinha / Guarda contigo meu coração / Hoje longe, muitas
légua / Numa triste solidão / Espero a chuva cair de novo / Pra mim vortar
ai pro meu sertão / Quando o verde dos teus olhos / Se espalhar na
plantação / Eu te asseguro não chore não, viu / Que eu voltarei, viu / Meu
coraçâa (GONZAGA, 1947).

A escassez de água e vegetação molda a população nordestina, que se submete a atividades (agricultura, urbanização, vestimenta, entre outras) relacionadas somente ao sertão, quando comparadas a outras porções do território nacional. A vida regula-se, então, a essa adequação. É por meio desse processo que o sertanejo adquire seus aspectos particulares de convívio em sociedade.

Conforme salientam Santos e Silveira (2006, p. 270),

A constante é o espaço, isto é, um conjunto indissociável, solidário, mas também contraditório, de sistemas de objetos e sistemas de ações. Poderíamos, grosseiramente - e como sugestão de um debate -, reconhecer a existência de quatro Brasis: uma Região Concentrada, formada pelo Sudeste e pelo Sul, o Brasil do Nordeste, o Centro-Oeste e a Amazônia.

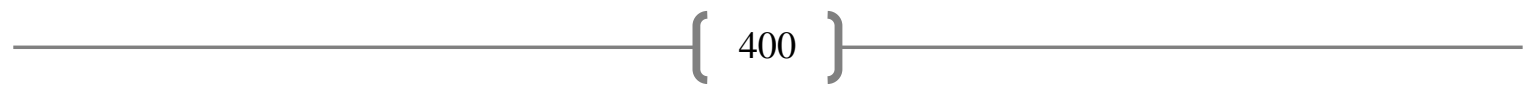

RIET- ISSN 2676-0355, Dourados, v. 2, n. 2, p. 391 a 408, jan./jun., 2021 


\section{A música ensina: educação e multiculturalismo}

Essa constante adaptação ao meio natural e a modificação do espaço pela atividade humana formam as particularidades presentes na população em espaços diferentes de um mesmo território. A divisão tradicional do Instituto Brasileiro de Geografia e Estatística (IBGE) já não congrega todas as relações das diferenças regionais. Por isso, a regionalização trazida por Milton Santos e Maria Laura Silveira exprime de maneira mais eficaz as semelhanças socioculturais de nossa nação.

\section{A Cultura Gaúcha e Missioneira}

A cultura gaúcha é composta por diversos elementos: as tropeadas e a lida com o gado, a ocupação do pampa e as disputas territoriais que aqui ocorreram, o Rio Guaíba e o processo de colonização da capital do estado, o fronteiriço Rio Uruguai e a disputa pelas demarcações territoriais e o poderio econômico da bacia do Prata, etc. A história do Rio Grande do Sul, bem como a formação das Missões Jesuíticas-Guarani, criadas pela Companhia de Jesus (ordem católica espanhola formada no contexto da contrarreforma), está presente na música tradicionalista e nativista do estado do Rio Grande do Sul.

De acordo com Pesanvento (1984, p. 12),

Os Sete Povos tornaram-se importantes centros econômicos, onde, além da erva-mate e criação do gado, realizavam-se trabalhos de fiação, tecelagem, metalurgia, ofícios vários e trabalhos artísticos, com destaque na arquitetura e escultura. Usando de habilidade, num processo de adaptação da cultura indígena anterior ao aldeamento, os missionários nomearam seus caciques como chefes de setores de serviços administrativos. Aos poucos, com o florescimento dos Sete Povos e o desenvolvimento dos quadros administrativos necessários à organização de cada redução, os novos cargos, agora eletivos, foram substituindo as antigas lideranças.

Os povos originários utilizavam a música para adoração aos elementos espirituais associados aos fenômenos da natureza. Nas reduções, fez-se a apropriação dos saberes e conhecimentos europeus às práticas indígenas. Neste processo, os índios reduzidos ${ }^{3}$ (re)adaptaram a arte barroca, passando a esculpir os santos católicos, produzir a cestaria, a cerâmica jesuítico-guarani e fabricar instrumentos musicais segundo os modelos europeus (violão, harpa, piano, lira, guitarra acústica, violinos, contrabaixos, cielos, entre outros).

Segundo Golin (2004), a música gaúcha reflete essa herança sócio-histórica e as canções exaltam a memória cultural:

\footnotetext{
${ }^{3}$ Nome dado aos índios que moravam nas Missões Jesuíticas. 401

RIET-ISSN 2676-0355, Dourados, v. 2, n. 2, p. 391 a 408, jan./jun., 2021 


\section{A música ensina: educação e multiculturalismo}

O movimento gauchesco chegou ao novo milênio tendo absolutamente consagrado uma estética do relacionamento. A sua maior expressão de massa é a música. Milhões de pessoas recebem desse cancioneiro padrões de valores, multiplicados nos meios de comunicação, nos clubes tradicionalistas e nos espaços de lazer. Na verdade, expandiram-se como expressões públicas, emuladas no cotidiano de todas as classes sociais. Entretanto, duvida-se que tal estética, pelo seu conteúdo, possa ter sobrevivência significativa na intimidade dos casais. Sua predominância popular, no fundo, domina e ocupa as mentes e, de algum modo, constrange e inibe a sensibilidade no aprendizado de gestos mais humanizados (GOLIN, 2004, p. 77).

A música Eu sou do Sul, de Elton Saldanha, representa a cultura gaúcha. Sua letra traz à tona vários elementos da história do Rio Grande do Sul relacionados às atividades laborais (agricultura e pecuária), à Revolução Farroupilha, quando se refere à "gente que veio da guerra", à produção de vinho da região serrana, ao Guaíba (rio de Porto Alegre de suma importância no processo de ocupação do estado, da questão fronteiriça e a experiência missioneira). Observe:

Eu sou do sul / É só olhar pra ver que eu sou do sul / A minha terra tem um céu azul / É só olhar e ver / Nascido entre a poesia e o arado / A gente lida com o gado e cuida da plantação / A minha gente que veio da guerra / Cuida dessa terra, como quem cuida do coração / Você que não conhece meu estado / Está convidado a ser feliz neste lugar / A serra te dá o vinho, o litoral te dá carinho / E o Guaíba te dá um pôr do sol lá na capital / A fronteira, meus hermanos, é prenda, cavalo e canha / Viver lá na campanha é bom demais / Que um santo missioneiro te acompanhe, companheiro / Se puder, vem lavar a alma no rio Uruguai (SALDANHA, 1996).

Quando são aparadas as arestas do romantismo e do tradicionalismo, que confrontam a veracidade histórica, a música gauchesca pode se tornar um poderoso meio de diversificação das metodologias escolares. A história do Rio Grande do Sul pode ser reconstruída a partir das reflexões surgidas com a análise das canções presentes na música gauchesca, processo que pode ocorrer pela mediação do professor.

\section{A Influência do tradicionalismo no Rock Gaúcho}

A Música Popular Gaúcha (MPG) ficou conhecida por dar um novo enfoque à música produzida no Rio Grande do Sul. O tema que veio à tona foi o cenário urbano, principalmente o da região metropolitana de Porto Alegre. Nesse contexto, novos artistas emergiram no cenário musical gaúcho. As temáticas se diversificam e os estilos (Música Popular Brasileira

RIET- ISSN 2676-0355, Dourados, v. 2, n. 2, p. 391 a 408, jan./jun., 2021 


\section{A música ensina: educação e multiculturalismo}

(MPB), pop e rock) contam novas histórias, entre as quais surgem algumas reinterpretações da música tradicionalista. É essa influência que será abordada neste tópico.

Nesse contexto, salienta Estivalet (2016, p. 67):

O rock no estado remonta suas origens desde final da década de 50 , onde surgiam grupos musicais locais que rejeitavam a vestimenta "gaudéria". Assim como em diversas partes do mundo, a juventude porto-alegrense foi impactada pelo surgimento de artistas e o estilo de vida rock n'roll. A partir dos anos 1960, a jovem guarda incentivou conjuntos locais à comporem em português, e evidentemente, os Beatles amplificaram a popularidade do estilo além de expandir as fronteiras criativas do gênero. Também desde essa época já se entendia a posição mercadológica marginal de Porto Alegre em relação à São Paulo e Rio de Janeiro, onde as bandas obtinham com maior facilidade um contrato com produtores e proximidade com a indústria fonográfica. Mais próximo ao final da década, os músicos roqueiros de Porto Alegre tiveram contato com rock psicodélico o movimento hippie via-Woodstock. Já na década de 1970, grupos ligados ao Tropicalismo de Tom Zé e Mutantes também foram à capital e influenciaram músicos que buscavam uma linguagem modernista.

Para uma possível análise da canção Amigo Punk, do grupo Graforréia Xilarmônica, é preciso alçar a análise não somente da letra, mas também da sua composição melódica. A letra mistura os elementos dos traços tradicionalistas no vocabulário composto pelas atividades do trabalho com o gado, a domesticação do cavalo como meio de transporte e os termos usados na linguagem do povo gaúcho, como pode-se notar:

Amigo punk / Escute este meu desabafo / Que a esta altura da manhã / Já não importa o nosso bafo / Pega a chinoca, monta no cavalo / E desbrava esta coxilha / Atravessa a Osvaldo Aranha / E entra no Parque Farroupilha / Amanhecia e tu chegavas em casa com asa / A tua mãe dá bom dia / E se prepara pra marcar / O gado com o ferro em brasa / E não importa se não tem lata de cola / Eu quero agora é sestear nos meus pelego / Com meu cavalo galopando campo afora / O meu destino é Woodstock, mas eu chego / Aonde eu ouço a voz da cordeona / Já escuto o gaiteiro puxando o fole / Vai animando a gauderiada no bolicho / Enquanto eu sigo detonando o hardcore (JORGE; BIRK, 1995).

Já o seu contexto melódico mistura elementos da milonga (ritmo gaúcho de influência argentina e missioneira), com os timbres pesados e solos de guitarra presentes no rock. Esta música exprime as influências sofridas pela banda: do rock internacional, do rock brasileiro produzido no resto do país e da música regional produzida no Rio Grande do Sul.

Devido ao apreço rock e pop anglófono e simultânea formação gaúcha, de música do interior, havia uma intenção de unir o que eles consideravam suas raízes e fazer da música do Rio Grande do Sul algo que soasse como

RIET- ISSN 2676-0355, Dourados, v. 2, n. 2, p. 391 a 408, jan./jun., 2021 


\section{A música ensina: educação e multiculturalismo}

a música pop internacional. Tal fenômeno pode já demonstrar, cerca de vinte anos antes da canção Amigo Punk ser gravada, uma tendência em convergir a cultura regional com o rock (ESTIVALET, 2016, p. 69).

Outro exemplo dessa influência é a canção Herdeiros da Pampa Pobre, composta por Vaine Darde. A música foi gravada pela primeira vez em 1990 pelo Gaúcho da Fronteira (músico nativista) e regravada pela banda Engenheiros do Hawaii (banda gaúcha de rock) no ano seguinte. A referida canção teve alcance e sucesso nacional em ambas as versões.

Mas que pampa é essa que eu recebo agora / Com a missão de cultivar raízes / Se dessa pampa que me fala a história / Não me deixaram nem sequer matizes? / Passam às mãos da minha geração / Heranças feitas de fortunas rotas / Campos desertos que não geram pão / Onde a ganância anda de rédeas soltas / Se for preciso, eu volto a ser caudilho / Por essa pampa que ficou pra trás / Porque eu não quero deixar pro meu filho / A pampa pobre que herdei de meu pai / Herdei um campo onde o patrão é rei / Tendo poderes sobre o pão e as águas / Onde esquecido vive o peão sem leis / De pés descalços cabresteando mágoas / O que hoje herdo da minha grei chirua / É um desafio que a minha idade afronta / Pois me deixaram com a guaiaca nua / Pra pagar uma porção de contas (DARDE, 1991).

Destarte, como uma tendência de toda a música brasileira produzida na década de 1990, a música criada no Rio Grande do Sul também absorveu os elementos regionais. As raízes da música nativista, seu legado e contexto, são encontrados na obra das bandas de rock, MPB e outros estilos.

\section{Multiculturalismo e Globalização}

A globalização surge como fenômeno econômico e transcende para os âmbitos sociais, políticos e culturais. As empresas transnacionais estabelecem os padrões de consumo, ritmo de trabalho, velocidade de produção e os valores estéticos. Nesse cenário, despontam as críticas a essa globalização perversa, que estabelece as desigualdades sociais, as hegemonias mundiais e a homogeneização cultural. Para Santos (2008):

Esse motor único se tornou possível porque nos encontramos em um novo patamar da internacionalização, com uma verdadeira mundialização do produto, do dinheiro, do crédito, da dívida, do consumo, da informação. Esse conjunto de mundializações, uma sustentando e arrastando a outra, impondo-se mutuamente, é também um fato novo. Um elemento da internacionalização atrai outro, impõe outro, contém e é contido pelo outro. (SANTOS, 2008, p.15).

RIET- ISSN 2676-0355, Dourados, v. 2, n. 2, p. 391 a 408, jan./jun., 2021 


\section{A música ensina: educação e multiculturalismo}

Nesse passo, as distâncias são "encurtadas" com a evolução do meio tecnológico, científico e informacional, sendo que as populações se conectam através dos fenômenos migratórios. Nesse tema, uma canção que pode contribuir na construção do aprendizado é a música Disneylândia, do Titãs, que sempre permeou a temática nas composições:

Filho de imigrantes russos casado na Argentina com uma pintora judia / Casou-se pela segunda vez com uma princesa africana no México / Música hindu contrabandeada por ciganos poloneses faz sucesso no interior da Bolívia / Zebras africanas e cangurus australianos no zoológico de Londres / Múmias egípcias e artefatos incas no museu de Nova York / Lanternas japonesas e chicletes americanos nos bazares coreanos de São Paulo / Imagens de um vulcão nas Filipinas passam na rede de televisão em Moçambique / Armênios naturalizados no Chile procuram familiares na Etiópia / Casas pré-fabricadas canadenses feitas com madeira colombiana / Multinacionais japonesas instalam empresas em Hong-Kong / E produzem com matéria prima brasileira para competir no mercado americano / Literatura grega adaptada para crianças chinesas da comunidade europeia / Relógios suíços falsificados no Paraguai vendidos por camelôs no bairro mexicano de Los Angeles Turista francesa fotografada seminua com o namorado árabe na baixada fluminense / Filmes italianos dublados em inglês com legendas em espanhol nos cinemas da Turquia / Pilhas americanas alimentam eletrodomésticos ingleses na Nova Guiné / Gasolina árabe alimenta automóveis americanos na África do Sul / Pizza italiana alimenta italianos na Itália / Crianças iraquianas fugidas da guerra / Não obtém visto no consulado americano do Egito / Para entrarem na Disneylândia (TITÃS, 1993).

Essa aculturação mundial é representada pela crítica do grupo ao seu tempo. Neste caso, mostra as discrepâncias populacionais, os fenômenos migratórios e as relações socioculturais oriundas desse processo. A associação dos "elementos globais" e a mistura das populações mundiais aparece a todo momento na canção. As grandes empresas transnacionais são exemplificadas e consumidas por todas as nações, e, dentro dessa ideia, não necessariamente pelas populações locais, mas sim pela mistura delas.

Também referente à Globalização, são inúmeros os problemas que surgem a partir da Urbanização desenfreada. A música Manguetown, do grupo de recife Chico Science \& Nação Zumbi, verbaliza a globalização no âmbito dos problemas ambientais. A letra exprime a supressão dos biomas naturais (nesse caso, o mangue):

Tô enfiado na lama / É um bairro sujo / Onde os urubus têm casas / E eu não tenho asas / Mas estou aqui em minha casa Onde os urubus têm asas / Eu vou pintando, segurando as paredes / No mangue do meu quintal / Manguetown / Andando por entre os becos / Andando em coletivos / Ninguém foge ao cheiro sujo / Da lama da manguetown / Andando por entre os becos / Andando em coletivos / Ninguém foge a vida suja / Dos 


\section{A música ensina: educação e multiculturalismo}

dias da Manguetown / Esta noite sairei, vou beber com meus amigos / E com as asas que os urubus me deram ao dia / Eu voarei por toda a periferia / Vou sonhando com a mulher / Que talvez eu possa encontrar / E ela também vai andar na lama do meu quintal / Manguetown / Fui no mangue catar lixo / Pegar caranguejo / Conversar com urubu (FRANÇA; MAIA, 1996).

Ainda pela ótica de Milton Santos (2008), esse sistema de forças pode levar a pensar que o mundo se encaminha para algo como uma homogeneização, uma vocação a um padrão único. Isso ocorreria devido, de um lado, à mundialização da técnica, de outro, à mundialização da mais-valia ${ }^{4}$. Tudo isso é realidade, mas também - e sobretudo - tendência, porque em nenhum lugar, em nenhum país, houve completa internacionalização. O que há em toda parte é uma vocação às mais diversas combinações de vetores e formas de mundialização.

\section{Considerações finais}

Este artigo, através de uma perspectiva teórica, apresentou possibilidades de reflexões sobre como as composições musicais podem ser um instrumento lúdico e educacional para compreensão do contexto cultural, político, social e econômico ao qual os compositores estão inseridos no momento de criação. As canções presentes na produção artística da sociedade brasileira representam um instrumento de resgate ao patrimônio cultural, uma herança que, juntamente com outros elementos, caracteriza os diferentes grupos humanos, bem como estabelece pontos de aproximação entre as diversas culturas por meio da música.

Despertar possibilidades sobre a riqueza das diferentes expressões musicais e as sugestões educacionais que emergem desse processo foi o foco principal deste trabalho. Uma situação presente nas práticas educacionais está no pouco comprometimento dos educandos com a leitura. Para um povo que lê pouco, a poesia das letras das canções (de uma riqueza admirável) pode suprir essa lacuna (da poesia escrita).

Além disso, do ponto de vista de políticas educacionais, os próprios Parâmetros Curriculares Nacionais propõem que os estudantes tenham a habilidade de reconhecer as diversas produções culturais no seu contexto histórico e cultural. Conhecer e analisar as

\footnotetext{
${ }^{4}$ A mais-valia representa a disparidade entre o salário pago e o valor produzido pelo trabalho. Dessa maneira, pode ser entendida como o trabalho não pago, ou seja, são horas que o trabalhador cumpre pelo valor (lucro) que ele gera ao dono da indústria e pelo quais ele não é remunerado. No sistema capitalista, com o afastamento do trabalhador de seu produto final, ele é incapacitado de medir o valor de seu trabalho, o que possibilita ao capitalista apropriar-se de parte desse valor (MARX, 2013)
}

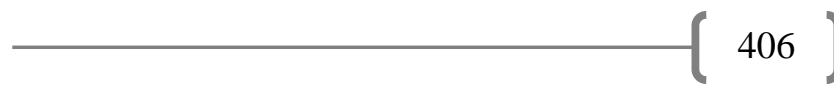

RIET- ISSN 2676-0355, Dourados, v. 2, n. 2, p. 391 a 408, jan./jun., 2021 


\section{A música ensina: educação e multiculturalismo}

canções que fazem parte da cultura brasileira pode representar um enriquecimento deste processo.

Para tanto, foram apresentadas algumas músicas como representação da cultura brasileira - nacional e local -, as quais são reflexos da sociedade multicultural atual. Neste sentido, foram propostas algumas possibilidades de articulações das canções apresentadas, com o contexto sócio histórico dos artistas e os conhecimentos escolares. O professor pode agir como mediador dessas reflexões, aproximando as canções de sua preferência, ou com as quais se sinta mais capacitado, e/ou familiarizado, para ser o interlocutor, com os conteúdos programáticos.

\section{Referências}

BHABHA, Homi K. O Local da Cultura. Belo Horizonte: Editora UFMG, 1998.

BRASIL, Parâmetros Curriculares Nacionais (PCNs). História. Ensino Médio. MEC/SEF. 1998.

CANCLINI, Néstor Garcia. Culturas Híbridas: estratégias para entrar e sair da modernidade. São Paulo: Edusp, 1998.

CANEN, Ana. Educação multicultural, identidade nacional e pluralidade cultural: tensões e implicações curriculares. Cadernos de Pesquisa, Rio de Janeiro, n. 102, p. 135-149, 2000.

COSTA, Oswaldo Rui da. Olhos Coloridos. In: SANDRA DE SÁ. Olhos coloridos. Rio de Janeiro: Som Livre, 1995. Faixa 9.

DARDE, Vaine. Herdeiro da Pampa Pobre. In: ENGENHEIROS DO HAWAI. Várias Variáveis. Rio de Janeiro: BMG, 1991. Faixa 2.

ESTIVALET, Felipe. Hibridações na canção Amigo Punk, da Graforréia Xilarmônica. Revista Sonora, Curitiba, v. 6, n. 11, p. 61-72, 2016.

FERREIRA, Aurélio Buarque de Holanda. Dicionário da Língua Portuguesa. 5. ed. Curitiba: Ed. Positivo: 2010.

FRANÇA, Francisco de Assis; MAIA, Lúcio. Manguetown. In: CHICO SCIENCE \& NAÇÃO ZUMBI. Afrociberdelia. Rio de Janeiro: 1996: Chaos. Faixa 12.

GEERTZ, Clifford. A interpretação das culturas. Rio de Janeiro: Ed. Guanabara, 1989.

GIL, Gilberto. In: GILBERTO GIL. Realce. Los Angeles: WEA, 1979. Faixa 7.

GOLIN, Tau. Identidades: questões sobre as representações socioculturais no gauchismo. Passo Fundo: Clio, Méritos, 2004.

GONÇALVES, Francisco César. Beradêro. In: CHICO CÉSAR. Aos vivos. São Paulo: Velas, 1995. Faixa 1.

RIET- ISSN 2676-0355, Dourados, v. 2, n. 2, p. 391 a 408, jan./jun., 2021 


\section{A música ensina: educação e multiculturalismo}

GONZAGA, Luiz. In: LUIZ GONZAGA. Vou pra roça. Rio de Janeiro: Victor, 1947. Faixa 2.

HALL, Stuart. A identidade cultural na pós-modernidade. 11. ed. Rio de Janeiro: DP\&A, 2006.

JORGE, Frank, BIRK, Marcelo. Amigo Punk. In: GRAFORRÉIA XILARMÔNICA. Coisa de

Louco II. Porto Alegre: Banguela Records, 1995. Faixa 10.

LIBÂNEO, José Carlos. Didática. 2. ed, São Paulo: Editora Cortez, 2013.

MARX, K. O Capital - Livro I - crítica da economia política: O processo de produção do capital. Tradução Rubens Enderle. São Paulo: Boitempo, 2013.

McLAREN, Peter. Multiculturalismo Crítico. 3. ed. São Paulo: Cortez, 2000.

McLAREN, Peter. Rituais na escola: em direção a uma economia política de símbolos e gestos na educação. 1. ed. Petrópolis: Vozes, 1991.

MORAES, José Geraldo Vinci. História e música: canção popular e conhecimento histórico.

Revista Brasileira de História. São Paulo, v. 20, n. 39, p. 203-221, 2000.

MOREIRA, Antonio Flávio Barbosa. Currículo, diferença cultural e diálogo. Educação \& Sociedade, Goiânia, n. 79, p. 15-38, 2002.

O RAPPA. Homem Amarelo. In: O RAPPA. Lado B Lado A. Rio de Janeiro: Warner Music, 1999. Faixa 9.

PESAVENTO, Sandra Jatahy. História do Rio Grande do Sul. 3. ed. Porto Alegre: Mercado Aberto, 1984.

SALDANHA, Elton. Eu sou do sul. In: OSVALDIR \& CARLOS MAGRÃO. Osvaldir \& Carlos Magrão. Porto Alegre: 1996. ACIT. Faixa 7.

SANTOS, Boaventura de Sousa. Reconhecer para libertar: os caminhos do cosmopolitismo multicultural. Rio de Janeiro: Civilização Brasileira, 2003.

SANTOS, Milton; SILVEIRA, Maria Laura. O Brasil: território e sociedade no início do século XXI. 9. ed. Rio de Janeiro: Record, 2006.

SANTOS, Milton. Por uma outra globalização: do pensamento único à consciência universal. 15. ed. Rio de janeiro: Record, 2008.

SILVA, Marcio Ferreira da. A Conquista da Escola: Educação escolar e movimento dos professores indígenas. In: Em aberto. Brasília, 1994. Disponível em:

http://www.emaberto.inep.gov.br/ojs3/index.php/emaberto/article/view/2282. Acesso em: 31 nov. 2020.

WOODWARD, Kathryn. Identidade e diferença: uma introdução teórica conceitual. SILVA, Tomas Tadeu da; HALL, Stuart; WOODWARD, Kathryn. Identidade e diferença: a perspectiva dos estudos culturais. 13. ed. Petrópolis: Vozes, 2013. p. 7-72.

TITÃS, Disneylândia. In: TITÃS. Titanomaquia. Rio de Janeiro: WEA, 1993. Faixa 3.

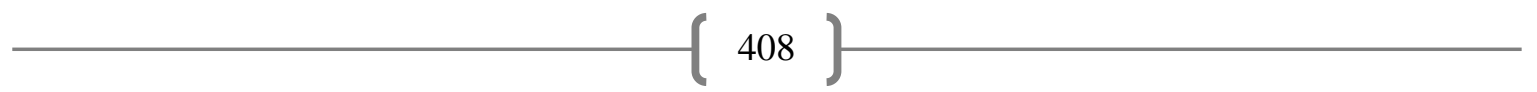

RIET- ISSN 2676-0355, Dourados, v. 2, n. 2, p. 391 a 408, jan./jun., 2021 